\title{
A Formação Jequitaí na região de Vila Boa, GO: exemplo de sedimentação por geleiras terminais no Neoproterozóico
}

\author{
The Jequitaí Formation at the Boa Vista Ridge, town of Vila Boa,
} GO: example of sedimentation by neoproterozoic terminal glaciers

\author{
Marco Antônio Caçador Martins-Ferreira ${ }^{1 *}$, José Eloi Guimarães Campos ${ }^{1}$, \\ Carlos José Souza de Alvarenga ${ }^{1}$
}

\begin{abstract}
RUMO: A Formaçáo Jequitá, localizada na base do Grupo Bambuí, constitui um importante registro das condiçôes climáticas e deposicionais do Meso/Neoproterozóico na borda Oeste do Cráton São Francisco. Sua ocorrência é registrada em contato discordante sobre as diferentes unidades que compóem o Grupo Paranoá e é lateralmente descontínua. Na região do município de Vila Boa, a Formação Jequitaí ocorre como uma sequência basal de camadas métricas de arenitos e grauvacas sobrepostas por uma camada decamétrica de diamictito maciço, seguido de uma camada métrica de arenito calcífero. Toda a sequência é recoberta por dolomitos de capa típicos de condiçôes pós-glaciais da Formação Sete Lagoas. O registro sedimentar sugere se tratar de depósitos glaciogênicos preservados em paleovales que sofreram rápida inundação após a sua deposiçẫo, indicando a ocorrência de geleiras terminais ainda em condiçôes continentais erodindo o Grupo Paranoá anteriormente à geração do Grupo Bambuí. As feiçôes petrográficas das rochas psefíticas sugerem a existência de diamictitos ressedimentados e a ocorrência de possíveis tilitos apenas de forma localizada.
\end{abstract}

PALAVRAS-CHAVE: Formação Jequitaí; diamictito; glaciação Neoproterozóica; esturtiano; geleiras terminais.
ABSTRACT: The Jequitai formation, located at the base of the Bambui Group, represents an important record of the climatic and depositional conditions of the Meso/Neoproterozoic at the Western border of the São Francisco craton. It occurs as a discordant contact over different units of the Paranoa Group and is laterally discontinuous. In the studied location the Jequitai Formation occurs as a basal sequence of metric sandstone and greywacke layers overlain by a decametric layer of massive diamictite followed by a metric calciferous sandstone layer. The whole sequence is covered by typical postglacial cap dolomites of the Sete Lagoas Formation. The sedimentary record suggests that it represents glaciogenic deposits preserved in gentle palaeovalleys that underwent fast flooding after its deposition, indicating the occurrence of terminal ice sheets in continental environment eroding the Paranoa Group prior to the generation of the Bambui Group. The petrographic features of the coarse rocks suggest the existence of resedimented diamictites and the occurrence of possible tillites facies only locally.

KEYWORDS: Jequitaí Formation; diamictite; Neoproterozoic glaciation; Sturtian; terminal glaciers.

${ }^{1}$ Instituto de Geociências, Universidade de Brasília - UnB, Brasília (DF): Campus Darcy Ribeiro, Brasília (DF), Brasil. E-mails: marcoc@unb.br; eloi@unb.br; alva1@unb.br *Autor correspondente

Manuscrito ID 15454. Recebido em: 31/05/2011. Aprovado em: 30/04/2013 


\section{INTRODUÇÃO}

O conhecimento detalhado sobre as rochas pertencentes à Formação Jequitaí é de grande importância para a caracterização do contexto climático, sedimentológico e geomorfológico da Faixa Brasília no Neoproterozóico, além de possibilitar o estudo de modelos de sedimentação glacial no Pré-cambriano. O fato de registrar o fim de um longo período erosional do Grupo Paranoá e o estágio inicial na retomada da deposiçáo que gerou toda a sequência pelitocarbonatada do Grupo Bambuí, eleva a sua importância estratigráfica e sedimentológica na evolução da Faixa Brasília. O estudo destas rochas pode proporcionar dados sobre a história da transição Meso/Neoproterozóica não preservada no registro sedimentar da regiáo e servir como camada guia entre o Meso e o Neoproterozóico.

A idade das rochas que compóem a Formaçáo Jequitaí tem sido atribuída ao período glacial Esturtiano, datado entre 700 e $800 \mathrm{Ma}$ (Santos et al. 2000, Babinski \& Kaufman 2003), que deixou registros glaciogênicos em escala global (Hambrey \& Harland 1985, Hoffman et al. 1998, Kennedy et al. 1998). No Brasil, ocorre em grandes áreas do Cráton São Francisco e faixas circundantes, inclusive na zona externa da Faixa Brasília, local de estudo deste trabalho.

O detalhamento litofaciológico realizado nesta pesquisa permitiu a individualização de seis litofácies, que serão apresentadas adiante. $\mathrm{O}$ objetivo do presente trabalho é documentar os dados disponíveis em campo a fim de caracterizar a variação vertical e lateral de litofácies e elaborar uma associação faciológica que permita caracterizar as condiçôes sedimentológicas e geomorfológicas em que as rochas da Formação Jequitaí foram depositadas na região da Serra da Boa Vista, município de Vila Boa (Figs. 1 e 2).

\section{CONTEXTO GEOLÓGICO REGIONAL}

A área estudada está situada na Zona Externa da Faixa de Dobramentos e Cavalgamentos Brasília, gerada no Ciclo Brasiliano, evento deformacional ocorrido há $600 \mathrm{Ma}$ (Dardenne 2000, Pimentel et al. 1999, 2000). A Faixa Brasília pertence à Província Estrutural do Tocantins e está próxima à borda ocidental do Cráton do São Francisco (Fig. 3).

A feição geomorfológica denominada Serra da Boa Vista é o resultado do processo erosivo de uma anticlinal de flanco falhado de escala quilométrica com vergência para Leste, onde afloram rochas do Grupo Paranoá. Nas sinclinais de mesma escala são expostas rochas do Grupo Bambuí.

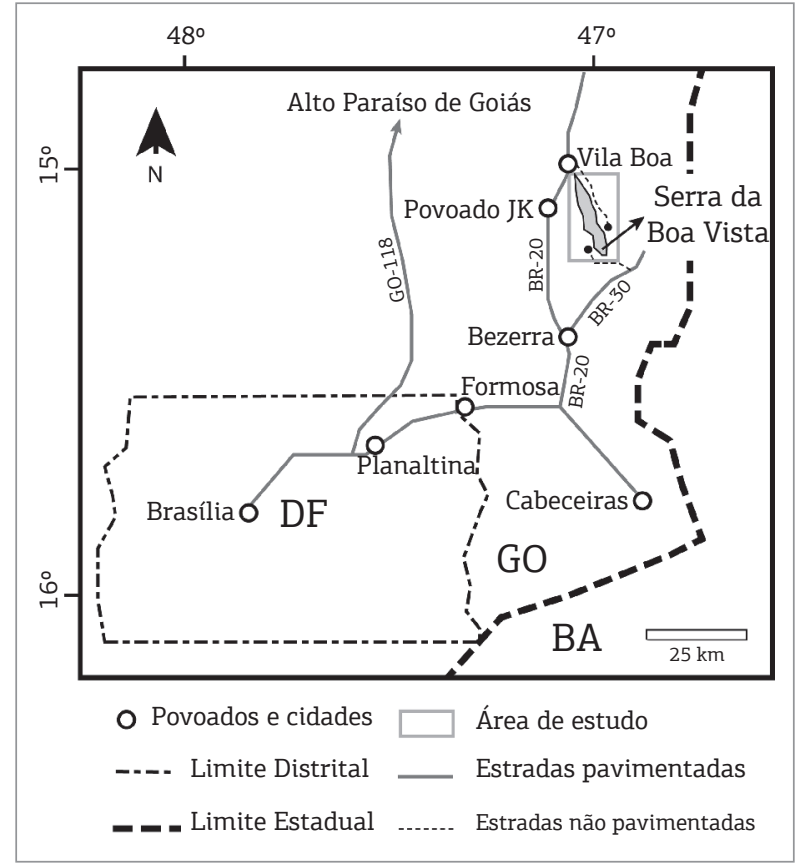

Figura 1. Localização e vias de acesso da área de estudo. Serra da Boa Vista, no município de Vila Boa. A partir de Brasília, o acesso à área de estudo se dá pela BR020 até o Distrito de Bezerra (GO). Então, para acessar a porção Oeste da serra é preciso entrar na BR-030 e seguir o rumo Noroeste por aproximadamente $10 \mathrm{~km}$ em estrada não pavimentada até a Fazenda Limoeiro. Para acessar a porção Leste da serra segue-se pela BR020 até a estrada não pavimentada, situada a $17 \mathrm{~km}$ após o Povoado JK, onde deve-se ir para Sudeste por aproximadamente $25 \mathrm{~km}$, até a Fazenda Padre Pio.

O Grupo Paranoá compõe uma sequência psamo-pelito-carbonatada de idade Meso/Neoproterozóica em torno de 1.100 a 900 Ma. Dardenne \& Faria (1995) propuseram uma coluna estratigráfica para o Grupo Paranoá composta por 11 unidades denominadas informalmente por letras, da base para o topo (Tab. 1).

Localmente, o Grupo Paranoá é correlacionável às descriçôes realizadas por Guimarães et al. (1986) na região de Formosa-Cabeceiras, que abrange a área deste estudo. A unidade basal é composta por quartzitos que gradam de grossos a finos e fazem contato gradual intercalado com a Unidade Ritmito Inferior, na qual quartzitos finos se intercalam com metassiltitos. Próximo ao topo dessa unidade são abundantes as lentes de calcário e dolomito, e sobrepondo o Ritmito Inferior, ocorrem arcóseos médios a muito grossos, por vezes seixosos, sobrepostos pela Unidade Ritmito Superior formada por quartzitos, metassiltitos e metargilitos alternados. A sucessão estratigráfica do Grupo Paranoá é importante no presente trabalho para a caracterização do paleo relevo da região no Neoproterozóico, um dos objetivos do estudo. A correlação estratigráfica entre as 


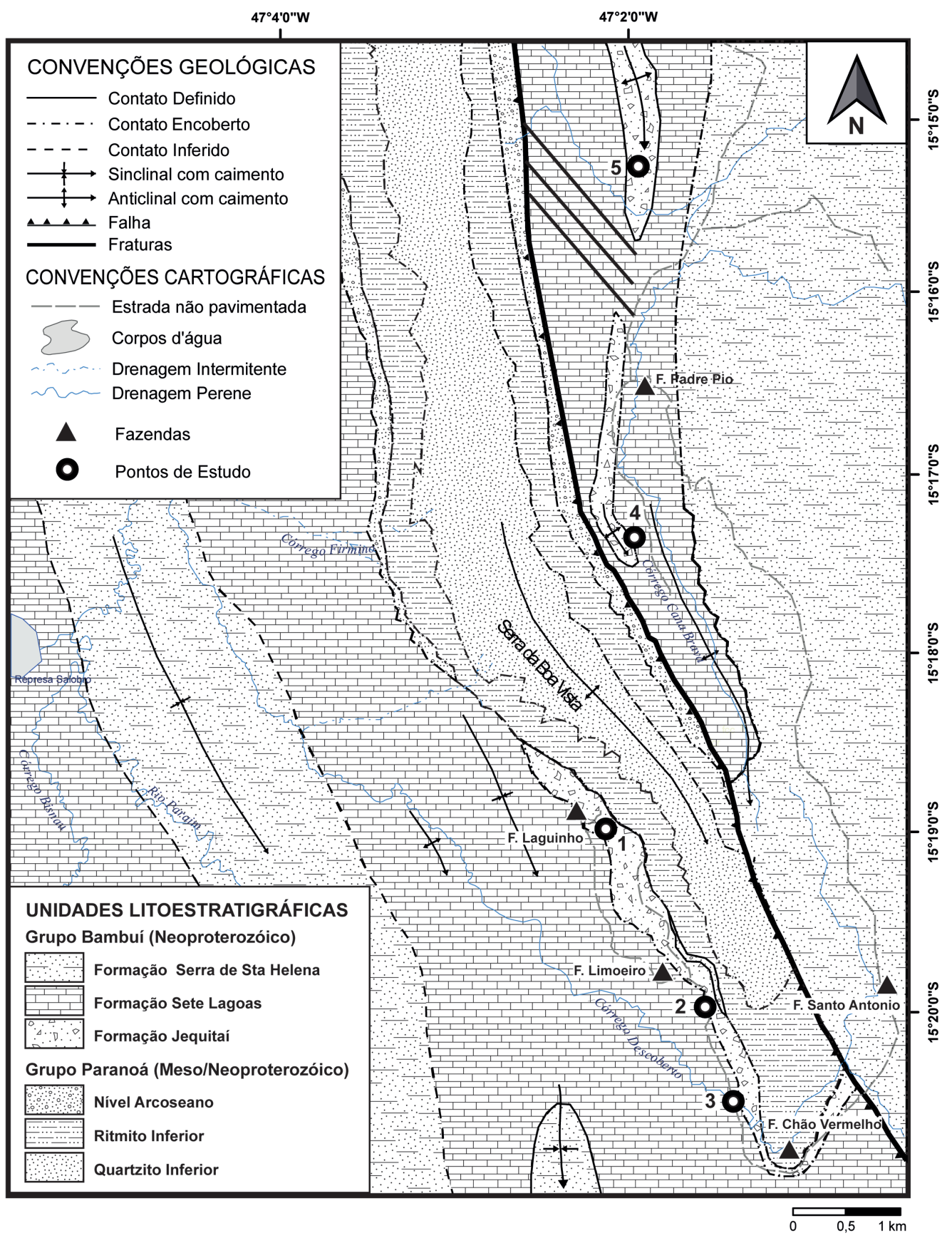

Figura 2. Mapa geológico da área mostrando os afloramentos estudados. (1) Toca da Onça (afloramento principal deste estudo). Coordenadas UTM SAD69:0282213/8305641; (2) Fazenda Limoeiro. Coordenadas UTM SAD69:0283182/8303560; (3) Córrego Descoberto. Coordenadas UTM SAD69:0283546/8302564; (4 e 5) Fazenda Padre Pio. Coordenadas UTM SAD69:0282533/8311974.

descrições de Faria \& Dardenne (1995) e Guimarães et al. (1986) na região de Bezerra é apresentada da Tab. 1.

Entre o topo do Grupo Paranoá e a base do Grupo Bambuí, que o sucede, ocorre de forma descontínua a Formação Jequitaí, recoberta por carbonatos dolomíticos (Alvarenga \& Trompette 1992, Alvarenga et al. 2007).
Alguns autores separam a Formação Jequitaí do Grupo Bambuí por questóes diversas. Couto \& Bez (1978) discutiram a questão com argumentos estratigráficos e paleoclimáticos. Contudo, a estratigrafia de sequências e a confirmação da possibilidade de gênese de carbonatos em ambientes frios (dolomitos de capa) permitem afirmar que 


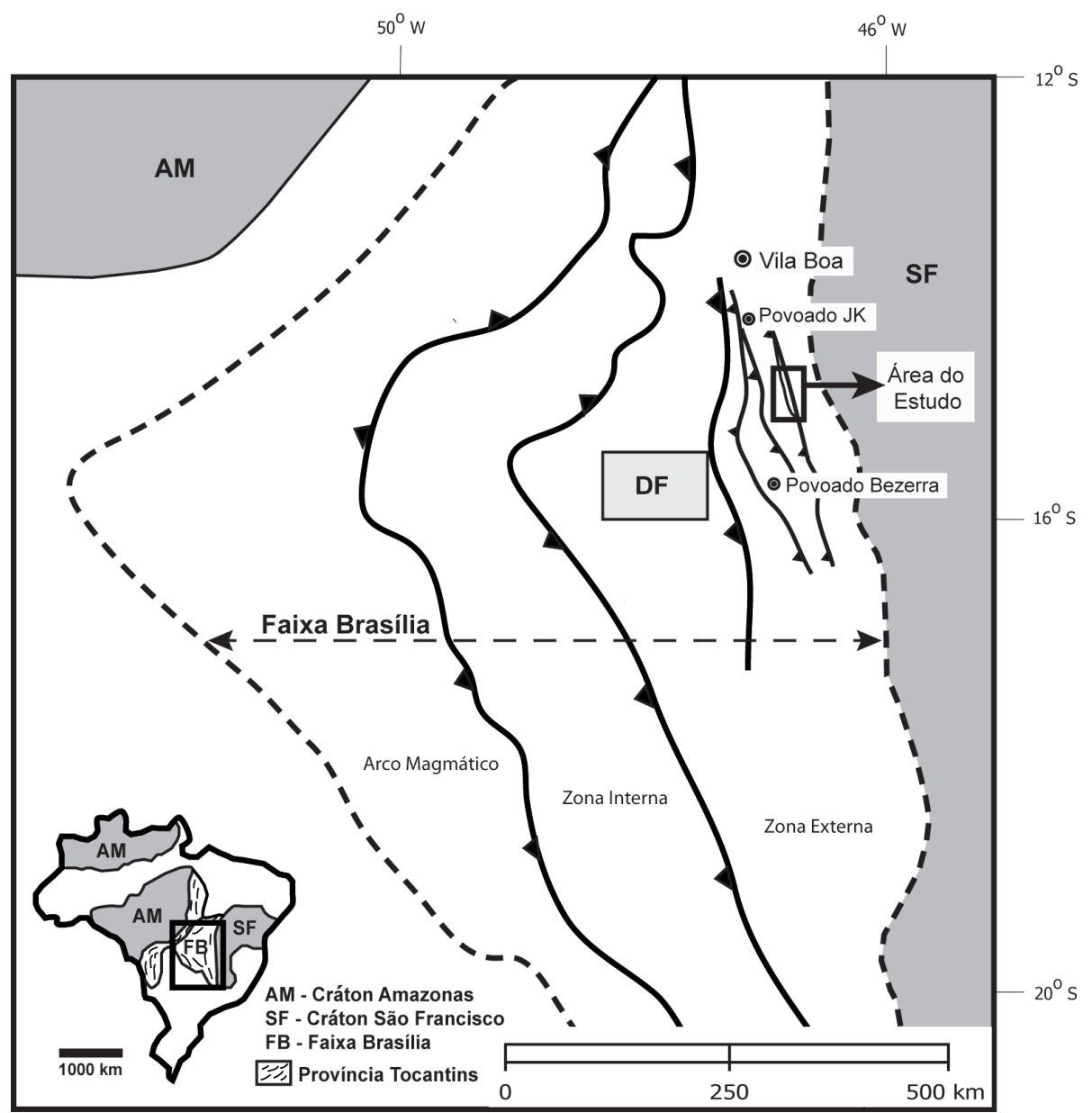

Figura 3. Mapa de localização da área de estudo no contexto regional.

rochas glaciogênicas e carbonatos estejam associados em termos ambientais e temporais, pertencendo à mesma sucessão sedimentar.

A Formação Jequitaí, na área deste estudo, é formada por arenitos limpos com estratificação cruzada, grauvacas rítmicas de maturidade textural variada, ritmitos com intercalaçôes de areias grossas e lâminas pelíticas, diamictitos maciços e arenitos calcíferos. Repousa em discordância erosiva sobre unidades distintas em paleovales do Grupo Paranoá, sendo, dessa forma, útil na caracterização do paleo relevo pré-brasiliano. Possui caráter descontínuo e localmente apresenta espessura máxima de $36 \mathrm{~m}$, podendo variar regionalmente de 0 a $150 \mathrm{~m}$ (Uhlein et al. 2004, Cukrov et al. 2005).

Diversos autores têm atribuído origem glacial às rochas da Formação Jequitaí (Uhlein et al. 1999, Martins-Neto et al. 1999, Rocha-Campos \& Hasuí 1981), baseados nas feiçôes sedimentares que esses registros apresentam e nas ocorrências correlatas em várias localidades. Sua localidade tipo (Jequitaí, MG) foi inicialmente interpretada como glacio-terrestre (Karfunkel \& Hoppe 1988) e posteriormente como glacio-marinho (Uhlein et al. 1999, Martins-Neto et al. 1999, Uhlein et al. 2004). Nas demais em que ocorre, a variaçáo dependendo das feiçôes que apresenta ou da diferença de interpretação de feiçôes similares por cada autor. Karfunkel \& Hoppe (1988) ilustram a heterogeneidade lateral dos sedimentos glaciogênicos na Formação Terra Branca, onde relatam tilitos terrestres (fácies Jequitaí) a Oeste, seguidos por fácies glaciomarinhas (fácies Cagaratiba) e, finalmente, sedimentos marinhos (fácies Turmalina) a Leste.

O presente trabalho considera que a formaçáo estudada pode representar contextos geológicos distintos nas diferentes localidades em que ocorre e, por isso, procura classificar o ambiente deposicional local com base na associação das fácies documentadas. Essa abordagem foi possível graças à descoberta do afloramento Toca da Onça, que se encontra em excelentes condiçôes de preservaçáo e apresenta perfil bastante completo da formação, podendo ser indicado como seção tipo na região do município Vila Boa. 
Tabela 1. Unidades litoestratigráficas do grupo Paranoá segundo Dardenne e Faria (1995) correlacionadas com as unidades descritas por Guimarães et al. (1986)

\begin{tabular}{|c|c|c|}
\hline $\begin{array}{l}\text { Unidades de } \\
\text { Dardenne \& } \\
\text { Faria (1995) }\end{array}$ & Descrição & $\begin{array}{l}\text { Unidades de Guimarães } \\
\text { et al. (1986) }\end{array}$ \\
\hline $\mathrm{PC}$ & Metassiltitos e metargilitos com lentes calcárias e participação arenosa & Ritmito superior \\
\hline R4 & $\begin{array}{l}\text { Ritmitos com quartzitos muito finos subordinados. Localmente ocorrem arcóseos } \\
\text { no topo }\end{array}$ & $\begin{array}{l}\text { Nível arcosiano } \\
+ \\
\text { Ritmito inferior }\end{array}$ \\
\hline Q3 & Quartzitos com intercalações argilosas laminares & Quartzito inferior \\
\hline R3 & Alternância de quartzitos muito finos e metapelitos & - \\
\hline A & Ardósias com lentes quartzíticas ocasionais no topo & - \\
\hline $\mathrm{S}$ & $\begin{array}{l}\text { Metassiltitos com níveis argilosos e intercalações de quartzitos, metarritmitos e } \\
\text { lentes de calcário na base e lentes de dolomito com estromatólitos no topo }\end{array}$ & - \\
\hline Q2 & Quartzitos médios a grossos na base e grossos a conglomeráticos finos no topo & - \\
\hline $\mathrm{R} 2$ & Alternância de metassiltitos, metargilitos e quartzitos muito finos a grossos & - \\
\hline Q1 & Quartzitos com intercalações de metarritmitos & - \\
\hline R1 & $\begin{array}{l}\text { Alternância de metassiltitos, metargilitos e quartzitos finos a médios, com } \\
\text { metamargas na base }\end{array}$ & - \\
\hline SM & Conglomerado matriz suportado & - \\
\hline
\end{tabular}

\section{DESCRIÇÃO DE LITOFÁCIES}

Em todas as litofácies descritas é comum a presença de clastos de granulometria seixo e bloco, principalmente provenientes do próprio embasamento local, de modo que a classificação de fácies utilizada no presente trabalho desconsidera estes clastos e enfatiza a granulometria predominante a fim de refletir melhor as propriedades petrológicas e sedimentares de cada fácies.

O afloramento da Fazenda Limoeiro foi usado anteriormente por Alvarenga et al. (2007) para diferenciaçáo isotópica entre os carbonatos dos grupos Bambuí e Paranoá, que são separados pela Formação Jequitaí quando esta está presente. Apresenta contato basal erosivo com a Unidade Nível Arcoseano do Grupo Paranoá e expóe diamictito de aproximadamente 15,0 m de espessura verdadeira recoberto por uma fácies psamítica de espessura mínima de $0,5 \mathrm{~m}$, ainda pertencente à mesma formaçáo e similar ao que ocorre no afloramento da Toca da Onça. A estrada que margeia este afloramento foi construída sobre o contato desta última com as rochas da Formação Sete Lagoas (sobrejacente) de modo que apenas a espessura mínima fosse mensurável. Nele, a fácies Diamictito possui clastos de quartzito, calcário e arcóseo do embasamento local.

Na Fazenda Padre Pio, a Formação Jequitaí apresenta contato basal erosivo com o Nível Arcoseano do Grupo Paranoá. O afloramento 4 é o único em que o contato de topo com os dolomitos de capa da Formação Sete Lagoas do Grupo Bambuí náo se encontra encoberto. Já o 5 possui grande extensão aflorante lateral ao longo do eixo Norte-Sul de anticlinal de escala hectométrica, além de abundantes seixos e blocos de calcário e dolomito e, eventualmente, de arcóseo, praticamente ausentes no afloramento da Toca da Onça (afloramento 1), onde predominam clastos de quartzito e dolomito. Este fato corrobora com a constatação de que há grande predominância de clastos do embasamento local, com exceção do quartzito, transportado a maiores distâncias. $\mathrm{O}$ afloramento 3 , à beira do Córrego Descoberto e próximo à ponte sobre ele, não é representativo para estudos faciológicos detalhados por sua pouca exposiçâo, mas permite confirmar a continuidade lateral da Formação Jequitaí para Sul.

A exposição da Formação estudada na localidade Toca da Onça foi escolhida como afloramento tipo do presente trabalho. Trata-se de uma cavidade natural formada pela dissoluçấo do carbonato dolomítico, que representa a base da Formação Jequitaí no local (Fig. 4A). No interior da cavidade, que acompanha o mergulho das rochas $\left(250^{\circ} / 40^{\circ}\right)$, foram observadas cinco litofácies bem preservadas, e mais uma no exterior da cavidade, recobrindo as demais. Do lado de fora observa-se um excelente afloramento do contato erosivo entre o dolomito do topo da unidade Ritmito Inferior do Grupo Paranoá e o Diamictito (Fig. 4B). À medida que se adentra na Toca da Onça, observa-se o surgimento de fácies mais basais em contato com o dolomito (Fig. 4C), de modo que as rochas que compóem o teto da cavidade variam desde um diamictito rico em clastos na entrada (Fig. 4D) a arenitos limpos no fundo da mesma, passando por ritmitos e grauvacas, que serão apresentados da base para o topo a seguir.

\section{Litofácies Arenito Grosso (Ag)}

Esta fácies forma camadas pouco espessas $(1 \mathrm{~m})$ e lateralmente contínuas, tendo sido observada por aproximadamente $10 \mathrm{~m}$ já na porção mais profunda da Toca da Onça. É composta por arenitos grossos a muito grossos de coloração intercalada branca e cinza escuro, o que evidencia 

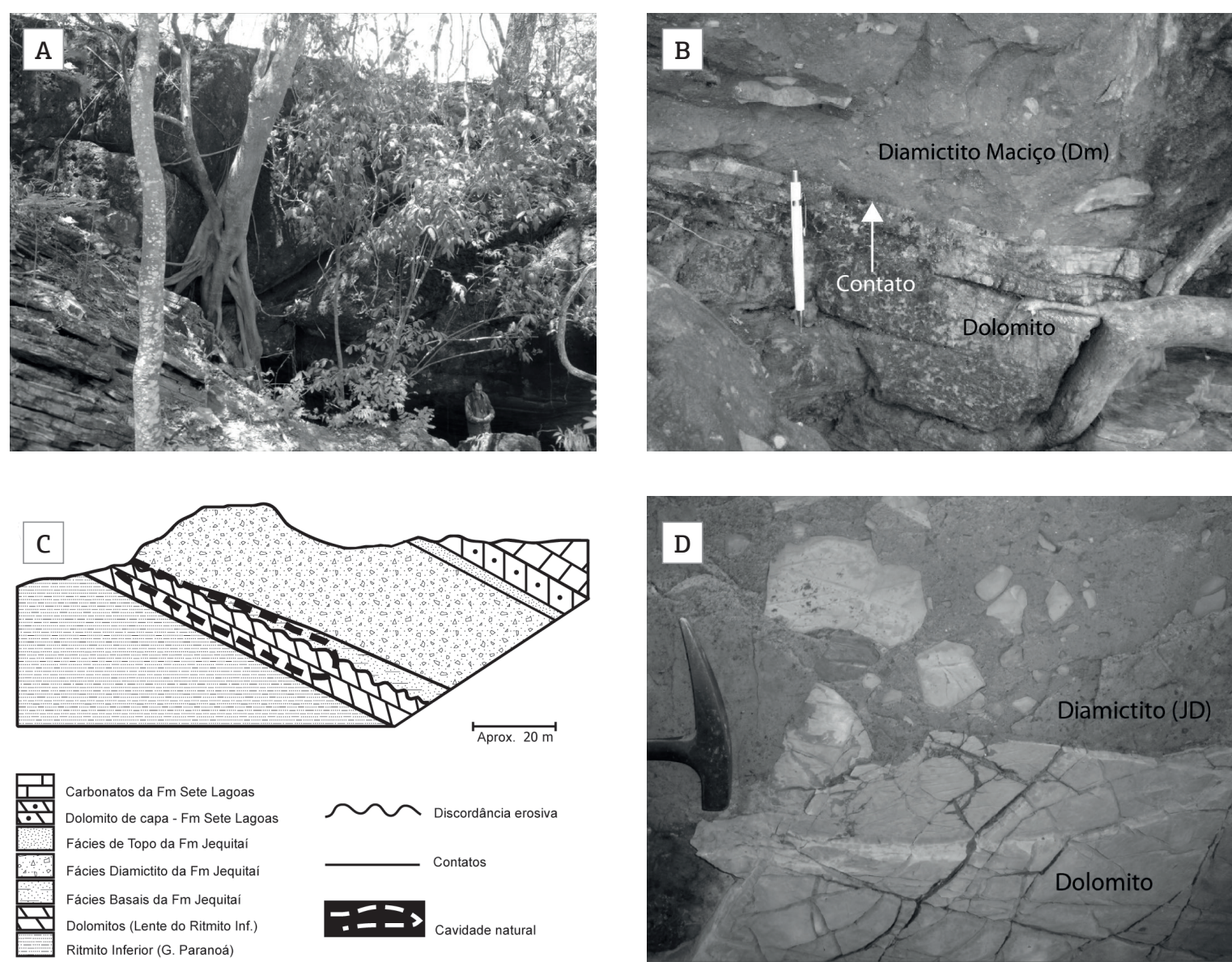

Figura 4. (A) Entrada da cavidade natural Toca da Onça (canto inferior direito). Notar o dolomito do topo do Ritmito Inferior (Grupo Paranoá) em contato direto com o diamictito no canto inferior esquerdo; (B) Contato erosional entre o dolomito do topo do Ritmito Inferior (Grupo Paranoá) e a fácies Diamictito Maciço (Dm). Notar clastos do dolomito suspensos no diamictito com seus eixos maiores alinhados; (C) Perfil do afloramento Toca da Onça mostrando a posição da cavidade natural em relação à estratigrafia local; (D) Vista do teto da cavidade natural Toca da Onça logo na entrada. Contato entre o dolomito do topo do Ritmito Inferior (Grupo Paranoá) e a fácies Diamictito Maciço (Dm).

estruturas de estratificação cruzada de baixo ângulo (Fig. 5A) e pode conter lâminas decimétricas com até $10 \%$ de matriz pelítica intercaladas com lâminas mais limpas. Representa a fácies mais basal observada. Próximo ao contato inferior possui grande quantidade de clastos tabulares do dolomito, que é base da Formação Jequitaí no local (Fig. 5B).

Microscopicamente, a $\mathrm{Ag}$ apresenta clastos de quartzo com intensa recristalização, onde se encontram eventuais inclusôes de microclínios. Entre todas as demais fácies, é a que apresenta melhor grau de selecionamento e arredondamento do quartzo (este último influenciado pela recristalização). Os contatos entre os grãos são planares a côncavo-convexos, com evidências de rotação. Localmente ocorrem clastos de siltitos, argilitos e silexitos de granulometria areia média a grossa e grãos dispersos de granulometria areia muito fina de turmalina, zircão e muscovita.

\section{Litofácies Arenito Grosso Rico em Matriz Pelítica (Agm)}

Forma camadas delgadas de aproximadamente $0,5 \mathrm{~m}$ e lateralmente contínuas, tendo sido observada por aproximadamente $25 \mathrm{~m}$ em contato brusco bem definido sobre a fácies Ag. Possui aspecto maciço com granulometria areia grossa predominante e matriz síltico-argilosa superior a $15 \%$ de coloração amarelada característica. Contém clastos angulosos desde areia a seixo do dolomito basal e grânulos esparsos de silexito cinza escuro (Fig. 5C).

Microscopicamente, apresenta cimento calcífero abundante e localmente dolomítico. O quartzo é predominante e se encontra na fração areia muito fina a muito grossa, mas predominantemente grossa. É muito mal selecionado, e o grau de arredondamento, bastante variado. Todavia, apresenta lâminas em que o selecionamento é melhor e o grau 

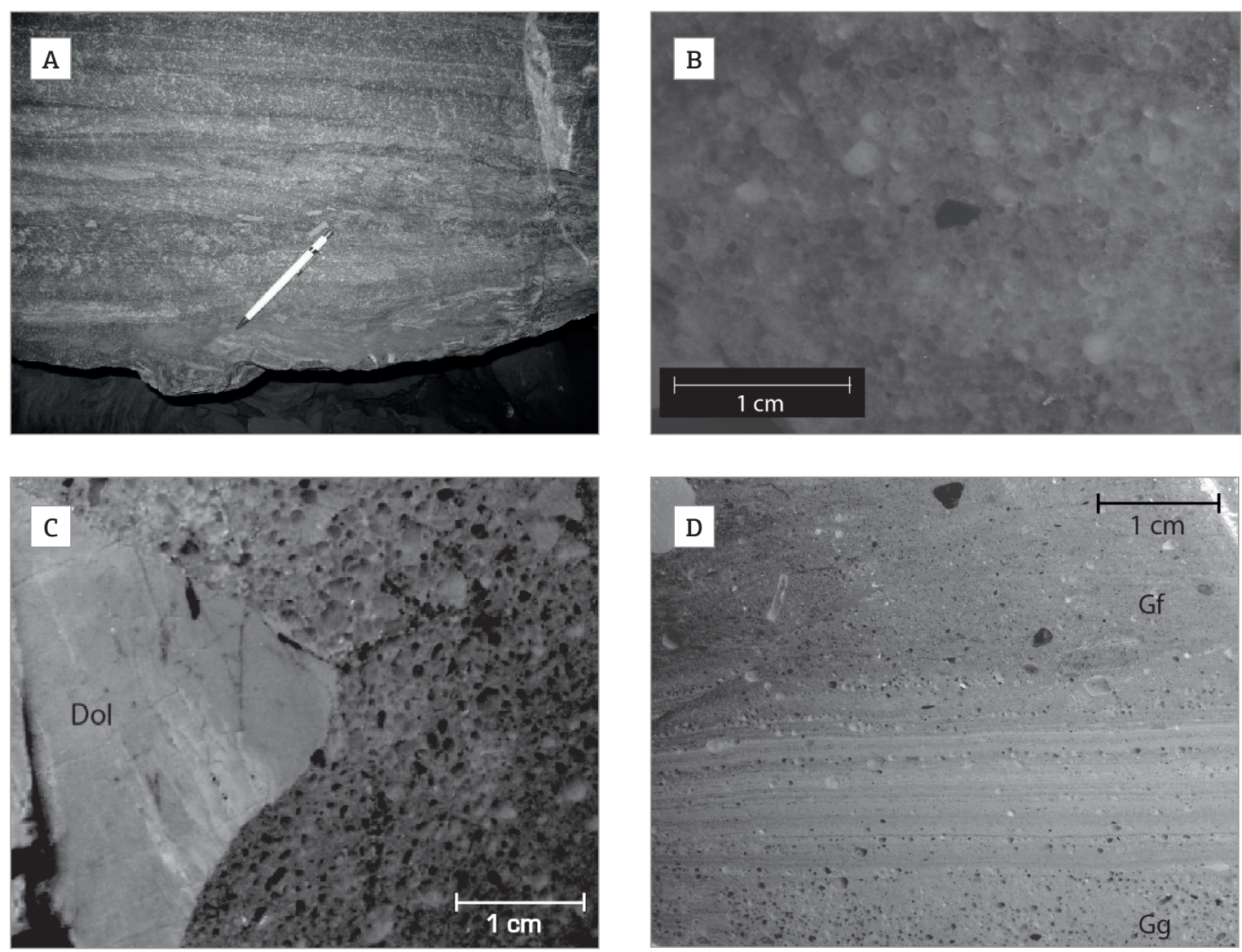

Figura 5. (A) Fácies Arenito Grosso (Ag) mostrando estratificação cruzada de baixo ângulo e clastos angulosos de dolomito do embasamento local; (B) Aspecto macroscópico da fácies Arenito Grosso (Ag) mostrando clastos arredondados de quartzo e pouca matriz; (C) Aspecto macroscópico da fácies Arenito Grosso Rico em Matriz Pelítica (Agm) mostrando mal selecionamento e matriz superior a 15\% com presença eventual de blocos de dolomito do embasamento local; (D) Aspecto macroscópico da transição entre as fácies Agm e Afm evidenciando variações de fluxo.

de arredondamento, mais uniforme, e possui grãos dispersos de carbonato, microclínio, zircão e siltitos contendo muscovita e feldspatos.

\section{Litofácies Arenito Fino Rico em Matriz Pelítica (Afm)}

Forma camadas delgadas de aproximadamente $0,6 \mathrm{~m}$ e lateralmente contínuas, tendo sido observada por aproximadamente $30 \mathrm{~m}$ em contato transicional rítmico com a fácies Agm. Apresenta laminação plano-paralela, granulometria areia fina predominante e matriz argilosa superior a $40 \%$ de coloração cinza esverdeada quando fresca. Contém clastos subangulosos desde seixo a grânulo do dolomito basal e clastos esparsos desde areia fina a grânulo de silexito cinza escuro (Fig. 5D).

Microscopicamente, apresenta cimento calcífero localizado e presença de clastos de grã areia muito fina a média de minerais opacos, argilito, carbonato, microclínio, turmalina, muscovita e, predominantemente, quartzo, com variação granulométrica de 0,1 a 1,0 mm, muito mal selecionado e desde anguloso a muito bem arredondado.

\section{Litofácies Arenito Grosso com Intercalações Pelíticas (Agi)}

Formado por camadas de até $2 \mathrm{~m}$ de espessura em contato abrupto na base e no topo, apresenta composição uniforme de camadas centimétricas de arenito grosso a muito grosso, imersas em matriz pelítica de cor clara, intercaladas com lâminas milimétricas de material pelítico de cor escura em estrutura plano-paralela irregular (Fig. 6A).

Microscopicamente, apresenta muscovita detrítica ao longo das lâminas de material pelítico e clastos predominantemente de quartzo mal selecionado subarredondado a 

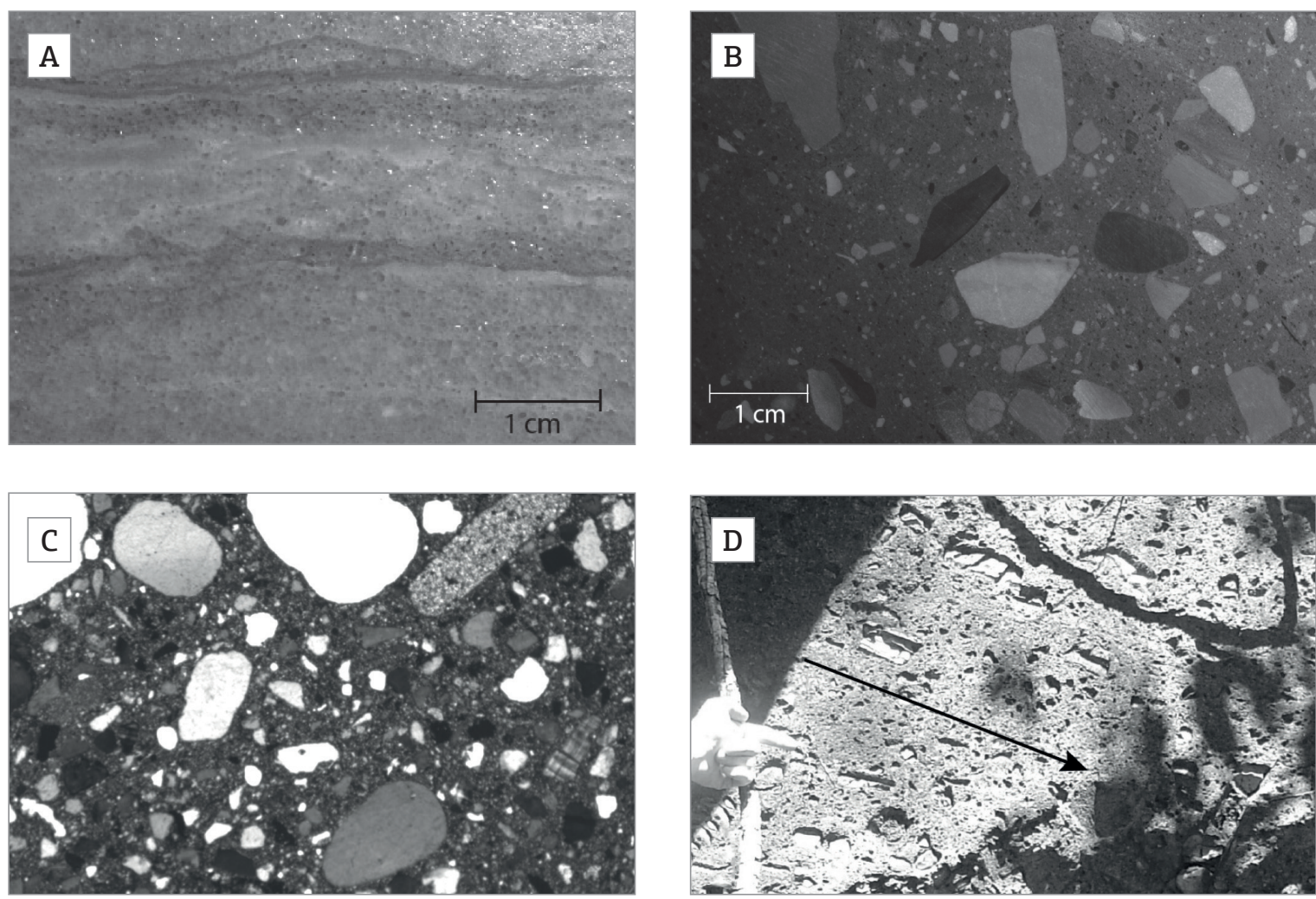

Figura 6. (A) Aspecto macroscópico da fácies Arenito Grosso com Intercalações Pelíticas (Agi); (B) Aspecto macroscópico da fácies Diamictito Maciço ( $\mathrm{Dm}$ ) mostrando mal selecionamento e clastos angulosos ao lado de clastos arredondados flutuando em matriz pelítica; (C) Aspecto microscópico com amento de 4 vezes da fácies Diamictito Maciço (Dm) mostrando clastos mal selecionados de carbonato, quartzo e feldspato com grau de arredondamento e grã variada dispersos em matriz pelítica carbonatada; (D) Tendência de orientação dos clastos menos esféricos da fácies Diamictito Maciço (Dm) sugerindo existência de fluxo durante a deposição.

arredondado e até $5 \%$ de microclínio arredondado de grã areia média a fina.

\section{Litofácies Diamictito Maciço (Dm)}

Representa a fácies de maior espessura no afloramento, chegando a $36 \mathrm{~m}$. Contém clastos de carbonato, quartzito, silexito e quartzo de granulometria e maturidade textural variadas imersos em matriz pelítica abundante (> 50\%) de coloração cinza escura. Dolomitos do embasamento local ocorrem na forma de blocos e matacôes angulosos. A fração arenosa fina a muito grossa é constituída predominantemente por quartzo bem arredondado. Possui, ocasionalmente, seixos de quartzitos facetados e estriados (Fig. 6B).

Microscopicamente, apresenta predominantemente clastos de dolomito do embasamento local de grã muito variada e, secundariamente, grãos de quartzo desde areia muito fina a muito grossa, bem arredondados a muito angulosos, de diferentes tipos: com extinção ondulante, extinção reta e com subgrãos. Possui ainda clastos de grã variada e todos os graus de arredondamento de silexito cinza escuro, além de microclínio, plagiocásio e siltitos, estes últimos geralmente subarredondados a arredondados, além de cimento/matriz carbonática generalizado (Fig. 6C).

\section{Litofácies Diamictito Estratificado (De)}

Ocorre nas porçốes superiores da formação em contato direto com o dolomito de capa, onde a litofácies Agc não está presente. Possui restrita espessura verdadeira, com no máximo $2 \mathrm{~m}$. Diferencia-se da fácies Dm por conter clastos de arcóseo em maior abundância e apresentar planos de estratificação bem evidentes de espaçamento centimétrico a decimétrico.

\section{Fácies Arenito Grosso Calcífero (Agc)}

Esta fácies recobre toda a sequência da Toca da Onça e tem espessura não superior a $2 \mathrm{~m}$. Está em contato abrupto com a fácies Dm e é composta por arenitos maciços, grossos, geralmente imersos em matriz pelítica/carbonática pouco abundante $(<10 \%)$. Ao contrário das demais fácies estudas, que estavam abrigadas no interior da Toca da Onça e se encontravam bem preservadas, a Agc não foi encontrada em condiçóes 
satisfatórias para a confecção de lâmina delgada e, por isso, não constam dados de suas propriedades microscópicas.

\section{ASSOCIAÇÃO FACIOLÓGICA E D̉ISCUSSÃO}

Apesar de ser regionalmente descontínua, a Formação Jequitaí ocorre de forma contínua tanto na borda Oeste quanto Leste da porção Sul da Serra da Boa Vista, exceto quando truncada por fraturas e uma falha de escala regional presentes no flanco Leste da serra. A descrição faciológica de três afloramentos principais, entre outros de menor importância, possibilitou a interpretação das condições deposicionais das rochas estudadas por meio da associação das fácies observadas. As mais basais afloram apenas na Toca da Onça, as quais podem ser descritas em detalhe.

A fácies Ag sugere condiçóes deposicionais de corrente trativa com alguma variação de energia, porém fluxo constante com intenso retrabalhamento dos sedimentos. A transição para a fácies Agm é abrupta e indica parada e retomada da sedimentação com maior energia gerando fluxo de detritos mais denso e formando rocha maciça. Próximo da transição com a fácies Afm, a Agm começa a apresentar lâminas milimétricas de material pelítico, que ficam mais frequentes até que se tenha transição definitiva para a fácies Afm, onde o fluxo de detritos se torna ainda mais denso, gerando uma rocha de aparência maciça com grande quantidade de matriz pelítica. Têmse nova parada e retomada, desta vez com a formação da fácies Agi, sugestiva de correntes trativas e fluxos de detrito intercalados em ciclos aparentemente mais rápidos. As feições preservadas na fácies Agi mostram indícios de retrabalhamento do sedimento anteriormente depositado pelos fluxos de detrito com a chegada de correntes trativas e vice-versa (Fig. 6A). A transição desta fácies para a Dm não foi observada, mas pela associação faciológica é presumido que seja abrupta e represente momentos de degelo mais rápido e intenso, em que blocos de gelo desprendidos da geleira e grandes fluxos de detrito carregaram grandes massas de sedimentos para as bacias marginais. Os indícios para tal interpretação são:

- o fato de a fácies Dm ser muito mais espessa que as demais;

- ser a única a apresentar clastos de quartzito facetado, de proveniência mais distal;

- apresentar tendência de orientaçáo do maior eixo dos clastos menos esféricos (Figs. 4B e 6D);

- o fato de conter clastos do embasamento local muito maiores, tendo sido observados com até $40 \mathrm{~cm}$ no seu maior comprimento.
A fácies Dm ocorre nos afloramentos de maior espessura e em todos apresenta características muito semelhantes, exceto pela variação dos tipos de clastos, que é função da variação do embasamento local. Já a fácies De ocorre com pouca espessura verdadeira $(1,5 \mathrm{~m})$ diretamente sobre o embasamento e em contato de topo direto com o dolomito de capa. A sua posição estratigráfica, a ausência das fácies basais (Ag, Agm, Afm, Agi, Dm) e superior (Agc) bem como sua estrutura bem estratificada de espaçamento variado sugerem que a fácies represente variação lateral da Dm depositada ocasionalmente em porçóes mais elevadas do terreno durante os grandes eventos de degelo responsáveis pela fácies maciça nas porçôes mais profundas dos paleovales.

A fácies Agc é lateralmente descontínua, pois não ocorre na Fazenda Padre Pio e apresenta cimento calcífero que pode ser de origem conata ou tardia, já que é recoberta por carbonatos. A sua posição estratigráfica permite sugerir, à partir dos dados levantados pelo presente estudo, que se trata de uma fácies depositada em um período tardio do derretimento das grandes massas de gelo, podendo representar o fim do período de deglaciaçáo e, apenas sobre as áreas de relevo mais baixo, sobre os maiores pacotes de diamictitos maciços.

A presença de fragmentos de feldspatos observáveis somente por meio de microscopia e a ausência de clastos de rochas que contenham feldspatos são indícios da origem distal dos sedimentos da Formação Jequitaí na Serra da Boa Vista, assim como a presença de grãos de quartzo com subgráos e/ou extinçáo ondulante, revelados pela petrografia microscópica e relacionados a rochas metamórficas ou a veios de quartzo, inexistentes na Faixa Brasília anteriormente ao Neoproterozóico. Em estudo de proveniência por zircôes detríticos da Formação Jequitaí, Rodrigues (2008) sugeriu o Cráton São Francisco como principal fonte desses sedimentos, com contribuiçôes predominantemente Paleoproterozóicas e alguma contribuição Mesoproterozóica.

Em sedimentos náo glaciais de origem distal seria esperada maturidade textural e grau de selecionamento bem maiores que os encontrados nos sedimentos estudados. Além disto, a presença de seixos facetados de quartzito, o fato de estarem recobertos por dolomitos de capa (Alvarenga et al. 2007) em toda a sua extensão ao longo da Serra da Boa Vista e a correlação com a mesma formação em locais onde ocorrem seixos pingados e pavimentos estriados (Cukrov et al. 2005) permitem afirmar com segurança que se tratam de rochas glaciogênicas.

A presença de fácies de fluxo de detritos e correntes trativas, a ausência de seixos pingados, a pouca espessura dos sedimentos e a riqueza de clastos atribuem características terrestres a esses sedimentos, fatos que podem ser confirmados pela presença de superfície de inundação entre a Formação Jequitaí e o dolomito que a recobre. Uma vez 
que o ambiente de sedimentação das rochas estudadas é terrestre e do dolomito de capa sobreposto é marinho raso, é necessária a existência de uma transgressão marinha após a deposição da Formação Jequitaí. $\mathrm{O}$ indício de tal evento transgressivo é representado por uma superfície de inundação que retrabalha os sedimentos não consolidados da fácies De, a qual foi observada em escala de afloramento na Fazenda Padre Pio. Esta estratificação plano-paralela de espaçamento decimétrico no diamictito é cortada por superfície irregular no contato com o dolomito de capa.

A associação de fácies aliada à correlação estratigráfica (Fig. 7) do estudo realizado permite sugerir um modelo de sedimentação por geleiras terminais em que ciclos sazonais de incremento na taxa de degelo de centros glaciais localizados sobre o Cráton São Francisco foram responsáveis pela sequência deposicional observada (Fig. 8).

Os dados levantados corroboram para a interpretação da paleogeografia da região de deposição das rochas estudadas como um vale amplo e aberto (Fig. 7), que teria recebido em sua porção mais profunda os sedimentos psamo -pelíticos das fases iniciais de degelos cíclicos progressivos e, posteriormente, fluxos mais intensos e densos, recobrindo áreas mais abrangentes do paleovale com diamictitos, em fases de maior taxa de degelo durante o período de deglaciação ocorrida no Esturtiano. Condiçóes de regime termal temperado sugeridas por Eyles et al. (1983), seriam capazes de provocar fusão rápida da geleira, gerando fluxo de detritos abundantes. Pode-se considerar ainda uma

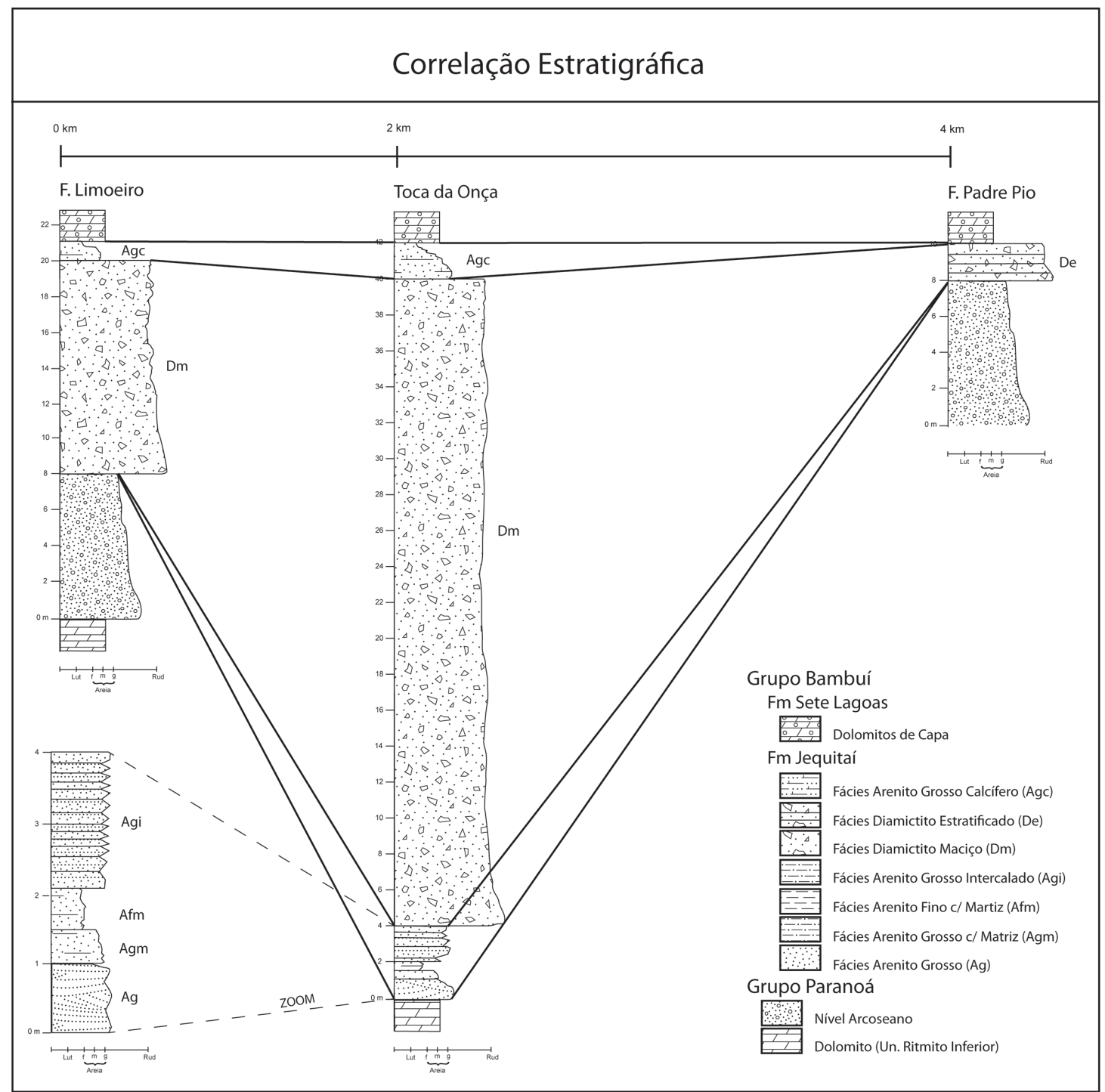

Figura 7. Correlação estratigráfica dos três afloramentos principais. 


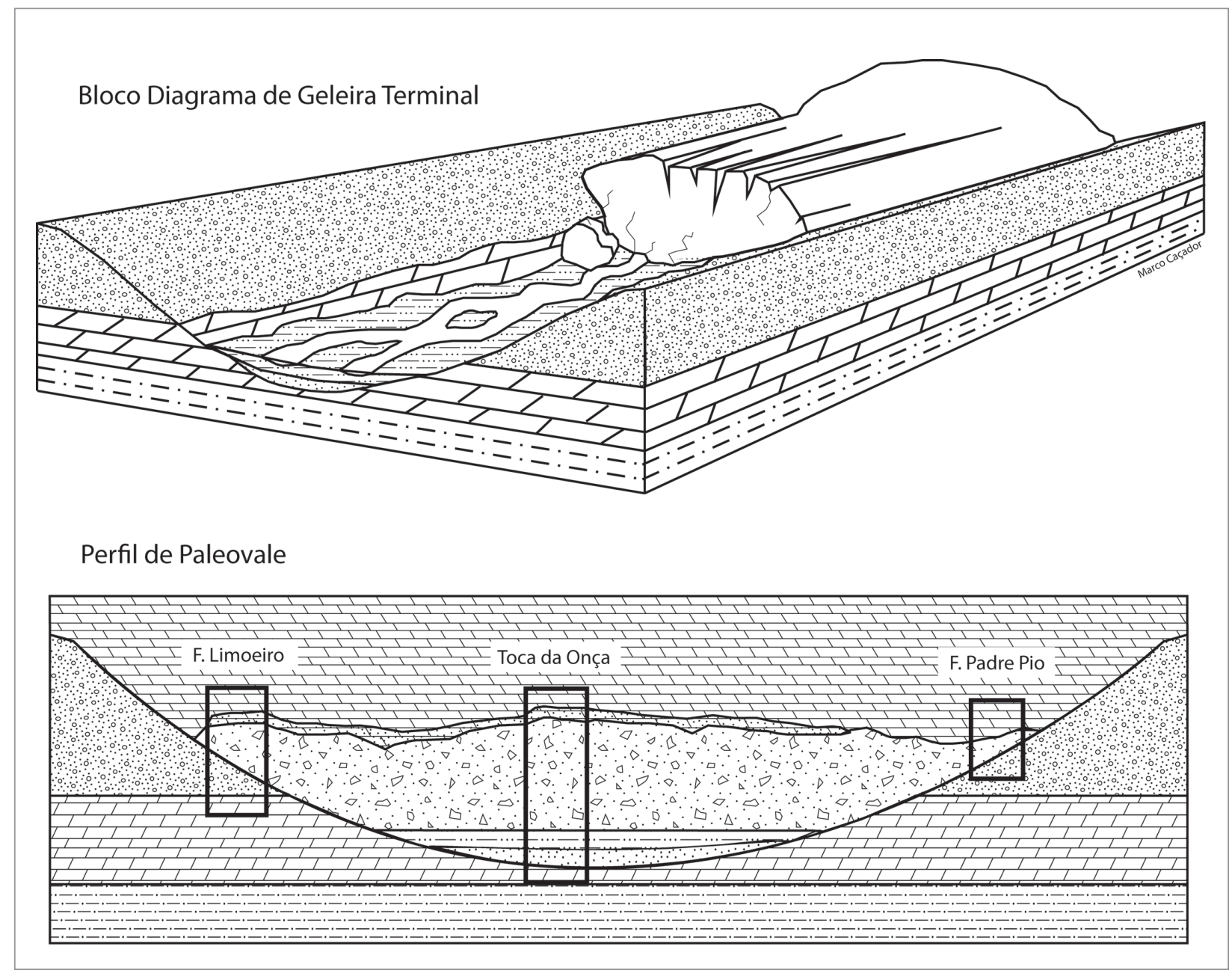

Figura 8. Bloco diagrama de geleira terminal proposto como modelo de ambiente e perfil de paleovale preenchido por sedimentos proposto como contexto paleogeográfico de sedimentação para a formação Jequitaí na região da Serra da Boa Vista, município de Vila Boa.

segunda hipótese, em que a fácies diamictito pode ter recoberto os paleovales do relevo Neoproterozóico suave da regiāo com grande espessura de sedimentos e ter sido erodida pela transgressão marinha subsequente, ficando preservada apenas no interior dos paleovales.

\section{CONCLUSÕES}

O estudo de associação de fácies das exposições da Formação Jequitaí na região do município de Vila Boa permite a apresentação das seguintes hipóteses:

- as feiçóes sedimentares dos diamictitos aflorantes na região, associadas à correlação estratigráfica com a Formação Jequitaí em outras regióes onde ocorrem pavimentos estriados e clastos pingados, bem como o fato de ocorrerem carbonatos de capa sobrepostos, permitem afirmar que se trata realmente de sedimentos glaciogênicos; a ausência de fácies marinhas e a presença de fácies características de fluxo trativo intercaladas com fácies de fluxo de detritos com maior densidade de sedimentos na base da formação permitem excluir a possibilidade de um ambiente de sedimentação glácio-marinho, como ocorre em outras regiôes, e sugerem um ambiente deposicional terrestre sedimentado durante períodos de deglaciação cíclica progressiva;

o aspecto maciço e a tendência de orientação dos eixos longos dos clastos do embasamento local do diamictito mais basal indicam que este pode ter sido transportado por blocos de gelo flutuantes nos rios pró-glaciais e/ou como morainas retrabalhadas por grandes eventos de fluxo aquoso;

- o aspecto estratificado nas porçôes de topo do diamictito (De) apontam aumento na ciclicidade e diminuição da quantidade de degelo após os grandes fluxos aquosos que formaram a fácies maciça; 
- a correlação estratigráfica dos três principais afloramentos estudados permite caracterizar a paleogeografia da região na época da deposição dos sedimentos estudados como vales amplos e abertos de direção aproximada E-W;

- o contexto geral fornece um excelente exemplo de sedimentação por geleiras terminais do período Esturtiano (-750 Ma) que marcam o fim de um longo período erosional do Grupo Paranoá e início da deglaciação responsável pela subida progressiva do nível eustático e consequente sedimentação do Grupo Bambuí;

- não foram encontradas boas exposiçóes da fácies Agc que permitissem seu maior detalhamento.
Recomenda-se o estudo detalhado dessa fácies, já que ela se revelou importante, apesar de não ser indispensável, para o estudo da Formação Jequitaí na regiāo.

\section{AGRADECIMENTOS}

Agradecemos à Professora Doutora Edi Mendes Guimarães pelas discussóes e à Universidade de Brasília pela concessão dos meios para a realização dos trabalhos de campo.

\section{REFERÊNCIAS}

Alvarenga C.J.S. de \& Trompette R. 1992. Glacially influenced sedimentation in the Later Proterozoic of the Paraguay belt (Mato Grosso, Brazil). Palaegeography, Palaeoclimatology, Palaeoecology, 92(1-2):85-105.

Alvarenga C.J.S., Giustina M.E.S.D., Silva N.G.C., Santos R.V., Gioia S.M.C.L., Guimarães E. M., et al. 2007. Variações dos isótopos de C e Sr em carbonatos pré- e pós-glaciação Jequitaí (Esturtiano), na região de Bezerra-Formosa, Goiás. Revista Brasileira de Geociências, 37(4 Suppl):147-155.

Babinski M. \& Kaufman A.J. 2003. First direct dating of a neoproterozoic post-glacial cap carbonate. In: South American Symposium on Isotope Geology, 4, Salvador, Short Papers, 1: 321-323.

Couto J.G.P. \& Bez L. 1978. Programa geocronologia do Grupo Bambuí. Belo Horizonte. Metais de Minas Gerais S.A. 31 p. (Relatório interno).

Cukrov N., Alvarenga C.J.S., Uhlein A. 2005. Litofácies da glaciação neoproterozóica nas porções sul do Cráton do São Francisco: exemplos de Jequitaí (MG) e Cristalina (GO). Revista Brasileira de Geociências, 35(1):69-76.

Faria A. \& Dardenne M.A. 1995. Estratigrafia do Grupo Paranoá na região de Alto Paraíso de Goiás - São João D’Aliança - GO. In: Simpósio de Geologia do Centro-Oeste, 5, Brasília, Boletim, p.75-77.

Guimarães E.M., Dardenne M.A., Faria A., Coelho C.E.S., Piaulino P.O.V. 1986. Relações dos grupos Paranoá, Jequitaí e Bambuí na região de Bezerra (GO). In: Congresso Brasileiro de Geologia, 34, Goiânia. Anais, v. 3. p. 853-60.

Hambrey M.J. \& Harland W.B. 1985. The late Proterozoic Glacial Era. Palaegeography, Palaeoclimatology, Palaeoecology, 51(1-4): 255-272.

Hoffman P.F., Kaufman A.J., Halverson G.P., Schrag D.P. 1998. A Neoproterozoic snowball earth. Science, 281(5381):1342-1346.

Karfunkel J. \& Hoppe A. 1988. Late Proterozoic glaciation in central-eastern Brazil: synthesis and model. Palaegeography, Palaeoclimatology, Palaeoecology, 65(2):1-21.
Kennedy M.J., Runnegar B., Prave A.R., Hoffmann K.H., Arthur M.A. 1998. Two or four Neoproterozoic glaciations? Geology, 26(12):1059-1063

Martins-Neto M.A., Gomes N.S., Hercos C.M., Reis L.A. 1999. Fácies glaciocontinentais (outwash plain) na megassequência Macaúbas, norte da Serra da Água Fria (MG). Revista Brasileira de Geociências, 29:281-292

Pimentel M.M., Fuck R.A., Botelho N.F. 1999. Granites and the Geodynamic of the Neoproterozoic Brasília belt, central Brazil: a review. Lithos, 46:463-483.

Pimentel M.M., Fuck R.A., Jost H., Ferreira Filho C.F., Araújo S.M. 2000. The basement of the Brasília Fold Belt and the Goiás Magmatic Arc. In: Cordani U.G., Milani E.J., Thomaz Filho A., Campos D.A. (eds.) Tectonic Evolution of South America. Rio de Janeiro, Intern. Geol. Congr., p. 195-230

Rocha-Campos A.C. \& Hasuí Y. 1981. Tillites of the Macaúbas Group (Proterozoic) in central Minas Gerais and Southern Bahia, Brazil. In: Hambrey M.J. \& Harland W.B. (eds.). Earth's Pre-Pleistocene Glacial Record. Cambridge, Cambridge University Press. p. 924-927.

Rodrigues J.B. 2008. Proveniência de sedimentos dos grupos Canastra, Ibiá, Vazante e Bambuí - Um estudo de zircões detríticos e Idades Modelo Sm-Nd.. Tese de Doutorado, Instituto de Geociências, Universidade de Brasília, Brasília.

Santos R.V., Alvarenga C.J.S. de, Dardenne M.A., Sial A.N., Ferreira V.P. 2000. Carbon and oxygen isotope profiles across MesoNeoproterozoic limestones from central Brazil: Bambuí and Paranoá groups. Precambrian Research, 104:107-22.

Uhlein A., Alvarenga C.J.S., Trompette R., Dupont H.S.J.B., EgydioSilva, M., Cuckrov N., et al. 2004. Glaciação Neoproterozópica sobre o Cráton do São Francisco e faixas adjacentes. In: Mantesso Neto V., Bartorelli A., Carneiro C.D.R., Brito Neves B.B. (Orgs.). Geologia do Continente Sul-americano - Evolução da obra de Fernando Flávio Marques de Almeida. São Paulo, Beca, p. 539-553.

Uhlein, A., Trompette R., Alvarenga C.J.S. de. 1999. Neoproterozoic glacial and gravitational sedimentation on a continental rifted margin: The Jequitaí-Macaúbas sequence (Minas Gerais, Brazil). Journal of South American Earth Sciences, 12(5):435-451. 